\title{
Vancomycin induced acute kidney injury: a review of the literature
}

\author{
Kerry Anne Rambaran PharmD, Kristen Fuhrmann PharmD, BCPS-AQ ID, AAHIVP
}

\begin{abstract}
Vancomycin has been widely used for its activity against Gram positive bacteria and is often the first choice for methicillin-resistant Staphylococcus aureus (MRSA). The current guidelines recommend trough levels of $15-20 \mathrm{mcg} / \mathrm{mL}$ to treat these resistant organisms. Higher trough levels are synonymous with higher doses and in turn predispose patients to adverse events. The most commonly reported adverse event is nephrotoxicity and/ or acute kidney injury. If detected early, this insult is reversible. We review the literature on vancomycin nephrotoxicity in the adult medicine and critical care patients, highlighting risk factors and differences between continuous and intermittent dosing regimens.
\end{abstract}

Key words: vancomycin, acute kidney injury, continuous infusion

Vancomycin, a bactericidal glycopeptide, was first introduced in 1956 and is one of the most commonly used antibiotics in the US. It inhibits cell wall synthesis of Gram positive bacteria. According to the American Society of Health-System Pharmacists, the Infectious Disease Society of America, and the Society of Infectious Diseases Pharmacists, the current recommended guidelines for vancomycin dosing are $15-20 \mathrm{mg} / \mathrm{kg}$ given every 8 to 12 hours for most patients with normal renal function to achieve optimal trough concentrations no less than $10 \mathrm{mcg} /$ $\mathrm{mL}$ to avoid the development of resistance. ${ }^{1,2}$ The use of higher doses can cause adverse events, such as nephrotoxicity and acute kidney injury, in patients with normal baseline renal function, critically ill patients, and obese patients. There are numerous theories about vancomycin-induced nephrotoxicity, including oxidative stress and allergic interstitial nephritis. ${ }^{3,4}$

Corresponding author: Kristen Furhmann Contact Information: kristen.Furhmann@umchealthsystem.com

DOI: $10.12746 /$ swrccc 2016.0415.200
The most frequently used definition of vancomycin associated nephrotoxicity is a $50 \%$ increase in serum creatinine over the baseline level or a decrease in creatinine clearance of $\geq 50 \%$ from baseline for two consecutive days. ${ }^{4}$ Nephrotoxicity can develop within four days to three weeks after the start of therapy, and retrospective studies have shown that it resolves in the majority of cases if it is detected early and vancomycin is discontinued. ${ }^{5-7,8,9}$ The incidence of vancomycin associated nephrotoxicity ranges from $5 \%$ to $65 \% .^{10}$ Risk factors for vancomycin induced kidney injury include high dose therapy, prolonged therapy, obesity, concomitant use of other nephrotoxins (such as aminoglycosides), critical illness requiring ICU admission, the use of vasopressors, and high Acute Physiology and Chronic Health Evaluation II scores. ${ }^{3,11-12}$

Continuous infusion dosing regimens are often used to reduce the development of acute kidney injury of nephrotoxicity; however, the current literature provides conflicting results on this strategy. Cataldo and colleagues conducted a systematic review and meta-analysis comparing the effect of continuous 
infusions of vancomycin with intermittent infusions in adult patients with Gram positive infections. Their meta-analysis showed that vancomycin continuous infusions were associated with a lower risk of nephrotoxicity when compared with intermittent infusions. These authors suggested that this may be due to the use of lower doses to achieve the same steady state concentrations when compared to intermittent infusion dosing. ${ }^{13}$

A retrospective, single center observational study conducted from 2004 to 2008 evaluated the influence of vancomycin dose, serum trough concentrations, and dosing strategy on the evolution of acute kidney injury in critically ill patients. Vancomycin was prescribed for 303 patients during the study period, and 251 patients received vancomycin for $>96$ hours. A total of 158 patients prescribed vancomycin were included in the retrospective analysis. Patients included in the study had a median age of 57 years and mean APACHE II scores of $21.32 \pm 7.4 ; 66 \%$ were males. Most patients (91.8\%) received intermittent vancomycin infusions for a mean treatment duration of 158 hours. Fourteen patients developed new onset AKI after vancomycin treatment, ten of these patients also received other nephrotoxic drugs during vancomycin treatment, and 12 later died in the ICU. There were no significant differences in the development of new onset $\mathrm{AKI}$ and duration of vancomycin treatment; the median duration of vancomycin therapy was 175.5 hours (IQR 127.75-374.57). Patients with severe illnesses on admission, such as sepsis $(64.3 \%$ versus $36.1 \%, p=0.047)$ or ischemic heart disease $(35.7 \%$ versus $11.1 \%, p=0.023$ ), were more likely to develop AKI. A vancomycin trough level of $16.5 \mathrm{mcg} / \mathrm{dL}$ was found to be the threshold for new onset AKI by receiver operating curve characteristic analysis (sensitivity $=0.93$ and specificity $=0.60$ ). Significant independent predictors of new onset $A K I$ were the mean trough vancomycin concentration $(O R=1.1174, p=0.024)$ and the APACHE II score $(O R=1.141, p=0.012)$. Simultaneous use of aminoglycosides was the only nephrotoxic agent that was a significant predictor of new onset $\mathrm{AKI}(\mathrm{OR}=18.896, \mathrm{p}=0.002)$. Their multivariable analysis showed that continuous infusion with vancomycin was less likely to cause nephrotoxicity. The results in this study are consistent with previous studies which noted that elevated vancomycin trough levels are associated with nephrotoxicity. These results also suggest that patients who used nephrotoxic agents and vancomycin concurrently had 18.89 $(p=0.002)$ greater odds of developing AKI than those who did not. Using univariate analysis, higher peak, mean, and initial vancomycin trough concentrations were associated with $\mathrm{AKI}$; however, only the mean concentration was found to be an independent predictor of new onset $A K I$ in regression modeling (OR, 1.174, $p=0.024)$. The APACHE II score was identified as a significant independent predictor of new onset $\mathrm{AKI}$, and a one unit increase in APACHE II score was associated with a $14.1 \%$ increase in the odds of AKI. The limitations of this study include its inability to account for all potential confounders due to the inherent limitations of a retrospective study design, a relatively small sample size which might not capture all predictive factors, and the exclusion of patients with increased serum creatinine at baseline. ${ }^{14}$

In 2010, Man and colleagues did a systematic review comparing the safety and efficacy of continuous and conventional intermittent infusions of vancomycin. Nine studies with small sample sizes were included in this systematic review. Since the studies included in the review were heterogeneous and provided limited data to support the use of continuous infusions of vancomycin, theses authors concluded that continuous infusions of vancomycin for multidrug resistant Gram positive infections might not be better than intermittent infusions. Additionally, they reported that continuous infusions did not appear to be more cost effective than intermittent infusion dosing. ${ }^{15}$ A prospective multicenter randomized study which compared continuous versus intermittent infusions of vancomycin in severe Staphylococcal infections did not show any difference in renal function between the groups and concluded that any differences or changes in serum creatinine levels may indicate failure of therapy rather than vancomycin nephrotoxicty. ${ }^{16}$

The information below provides general dosing guidelines for vancomycin. A maintenance regimen of $15-20 \mathrm{mg} / \mathrm{kg} /$ dose with the frequency determined by current creatinine clearance is the accepted dosing method. There is no clinical utility of peak se- 
rum concentrations, and therefore these should not be routinely measured. Serum trough concentrations should be routinely measured and serve as a surrogate indicator of the AUC: MIC ratio. ${ }^{1}$ Dosing in renal impairment requires changes in dosing and monitoring methods and often requires a detailed reference

\section{UM UMC HEAITH SYSTEM Adult Vancomycin Guidelines}

\section{Empiric Dosing for Vancomycin}

Loading dose based on Total Body Weight (TBW)

- Dose= mg/kg (TBW)

- Indicated in seriously ill patients or in those with high trough goals

- Loading dose: $25-30 \mathrm{mg} / \mathrm{kg} \times 1$ dose (max $3 \mathrm{~g}$ )

Maintenance dose based on Total Body Weight (TBW)

- Maintenance dose: $15-20 \mathrm{mg} / \mathrm{kg}$ (initial $\max 2 \mathrm{~g}$ )

- Round dose to the nearest $100 \mathrm{mg}$

Empiric dosing interval based on renal function

\begin{tabular}{|c|c|}
\hline $\mathrm{CrCl}$ (mL/min) & Dosing Interval (hrs) \\
\hline$>100$ & Q8hr \\
\hline $75-100$ & Q12hr \\
\hline $50-74$ & Q18hr \\
\hline $20-49$ & Q24hr \\
\hline Dialysis & See Renal Dosing \\
\hline
\end{tabular}

${ }^{*} \mathrm{Q} 6 \mathrm{~h}$ dosing interval generally not used empirically

II. Levels and monitoring

In most cases only monitoring troughs is necessary. Clinical utility of peak levels in unclear.

- Peak levels may be obtained in patients requiring high troughs $(15-20 \mathrm{mcg} / \mathrm{mL})$, morbidly obese and burn patients

- Goal peak $30-40 \mathrm{mog} / \mathrm{mL}$

- Troughs should be drawn within 30 minutes prior to the $4^{\text {th }}$ dose (prior to the $3^{\mathrm{rd}}$ dose if dosing interval $>24 \mathrm{hr}$ )

- Peaks should be obtained 1 hour after the end of the infusion

- $\quad$ "rRandom levels should only be obtained in patients with severe renal insufficiency or those on dialysis ${ }^{* *}$ source and nephrology consultation. Although vancomycin has been associated with nephrotoxicity and acute kidney injury, causality has not been confirmed, especially in complex critically ill patients. A prospective randomized double blind trial would potentially clarify this important concern.

\begin{tabular}{|c|c|}
\hline Indication & Target Trough Range \\
\hline UTI, skin wound/abscess & $10-15 \mathrm{mcg} / \mathrm{mL}$ \\
\hline $\begin{array}{l}\text { Sepsis, bactermia, osteomyelitis, } \\
\text { pneumonia, endocarditis, MRSA }\end{array}$ & $15-20 \mathrm{mcg} / \mathrm{mL}$ \\
\hline
\end{tabular}

*** Target trough levels should be $>10 \mathrm{mog} / \mathrm{mL}$ to avoid resistance ${ }^{* * *}$

- If trough within goal range, re-check trough weekly (stable patients)

- Recheck trough if there are significant changes in renal function

- If trough levels are not within goal range then change in dose and/or frequency may be necessary

***For adjustments in dose and frequency pharmacy may be consulted ${ }^{* * *}$

III. Renal Dosing

- In critically-ill patients with renal insufficiency the initial loading dose (25-30 mg/kg) should not be reduced

- Subsequent dosing is based on renal function and serum trough concentrations

\begin{tabular}{|c|c|c|}
\hline CrCl & Dose & Frequency \\
\hline $\operatorname{CrCl}>50 \mathrm{~mL} / \mathrm{hrc}$ & $\begin{array}{c}15-20 \mathrm{mg} / \mathrm{kg} / \text { dose } \\
(750-1500 \mathrm{mg})\end{array}$ & $\mathrm{Q} 8-12 \mathrm{hr}$ \\
\hline $\operatorname{CrCl} 20-49 \mathrm{~mL} / \mathrm{hr}$ & $\begin{array}{c}15-20 \mathrm{mg} / \mathrm{kg} / \text { dose } \\
(750-1500 \mathrm{mg})\end{array}$ & $\mathrm{Q} 24 \mathrm{hr}$ \\
\hline $\operatorname{CrCl}<20 \mathrm{~mL} / \mathrm{hrc}$ & $15-20 \mathrm{mg} / \mathrm{kg} /$ dose & $\begin{array}{c}>24 \mathrm{hr} \\
\text { Based on } \\
\text { serum } \\
\text { concentration }\end{array}$ \\
\hline
\end{tabular}

- For Q8-12hr dosing, peak and trough should be drawn with $4^{\text {n }}$ dose

- For Q24hr dosing, peak and trough should be drawn with the $3^{\mathrm{r}}$ dose

- For intervals $>24 \mathrm{hr}$ a random level should be dcawn and patient should be re-dosed once random level falls $<15 \mathrm{mg} / \mathrm{L}$ 
Author Affiliations: Kerry Anne Rambaran is a resident in the School of Pharmacy at Texas Tech University Health Sciences Center in Lubbock, TX. Kristen Furhmann is a pharmacist at University medical Center in Lubbock, TX.

Submitted: 5/27/2016

Published electronically: 7/15/2016

Conflict of Interest Disclosures: None

\section{REFERENCES}

1. Rybak MJ, Lomaestro BM, Rotschafer JC, et al. Therapeutic monitoring of vancomycin in adults summary of consensus recommendations from the American Society of Health-System Pharmacists, the Infectious Diseases Society of America, and the Society of Infectious Diseases Pharmacists. Pharmacotherapy 2009;29(11):1275-1279. http:/www.ncbi.nlm.nih.gov/ pubmed/19873687. Accessed August 15, 2015.

2. Martin JH, Norris R, Barras M, et al. Therapeutic monitoring of vancomycin in adult patients: a consensus review of the American Society of Health-System Pharmacists, the Infectious Diseases Society of America, and the Society Of Infectious Diseases Pharmacists. Clin Biochem Rev 2010;31(1):21-24. http://www.pubmedcentral.nih.gov/articlerender.fcgi?artid $=2826264 \&$ tool $=$ pmcentrez $\&$ rendertype $=$ abstract. Accessed May 4, 2016.

3. Gupta A, Biyani M, Khaira A. Vancomycin nephrotoxicity: myths and facts. Neth J Med 2011;69(9):379-383. http:// www.ncbi.nlm.nih.gov/pubmed/21978980. Accessed May 22, 2016.

4. Carreno JJ, Kenney RM, Lomaestro B. Vancomycin-associated renal dysfunction: where are we now? Pharmacotherapy 2014;34(12):1259-1268. doi:10.1002/phar.1488.

5. Pritchard L, Baker C, Leggett J, Sehdev P, Brown A, Bayley KB. Increasing vancomycin serum trough concentrations and incidence of nephrotoxicity. Am J Med 2010;123(12):11431149. doi:10.1016/j.amjmed.2010.07.025.

6. Jeffres MN, Isakow W, Doherty JA, Micek ST, Kollef $\mathrm{MH}$. A retrospective analysis of possible renal toxicity associated with vancomycin in patients with health care-associated methicillin-resistant Staphylococcus aureus pneumonia. Clin Ther 2007;29(6):1107-1115. doi:10.1016/j.clinthera.2007.06.014.

7. Fanos V, Cataldi L. Renal transport of antibiotics and nephrotoxicity: a review. J Chemother 2001;13(5):461-472. doi:10.1179/joc.2001.13.5.461.
8. Hidayat LK, Hsu DI, Quist R, Shriner KA, Wong-Beringer A. High-dose vancomycin therapy for methicillin-resistant Staphylococcus aureus infections: efficacy and toxicity. Arch Intern Med 2006;166(19):2138-2144. doi:10.1001/ archinte.166.19.2138.

9. Farber BF, Moellering RC. Retrospective study of the toxicity of preparations of vancomycin from 1974 to 1981. Antimicrob Agents Chemother 1983;23(1):138-141. http://www.pubmedcentral.nih.gov/articlerender.fcgi?artid=184631\&tool=pmcentrez\&rendertype =abstract. Accessed May 22, 2016.

10. Ramírez E, Jiménez C, Borobia AM, et al. Vancomycin-induced acute kidney injury detected by a prospective pharmacovigilance program from laboratory signals. Ther Drug Monit 2013;35(3):360-366. doi:10.1097/FTD.0b013e318286eb86.

11. Meaney CJ, Hynicka LM, Tsoukleris MG. Vancomycin-associated nephrotoxicity in adult medicine patients: incidence, outcomes, and risk factors. Pharmacotherapy 2014;34(7):653-661. doi:10.1002/phar.1423.

12. Rybak MJ, Albrecht LM, Boike SC, Chandrasekar PH. Nephrotoxicity of vancomycin, alone and with an aminoglycoside. J Antimicrob Chemother 1990;25(4):679-687. http://www. ncbi.nlm.nih.gov/pubmed/2351627. Accessed May 22, 2016.

13. Cataldo MA, Tacconelli E, Grilli E, Pea F, Petrosillo N. Continuous versus intermittent infusion of vancomycin for the treatment of Gram-positive infections: systematic review and meta-analysis. J Antimicrob Chemother 2012;67(1):17-24. doi:10.1093/jac/dkr442.

14. Hanrahan TP, Kotapati C, Roberts MJ, et al. Factors associated with vancomycin nephrotoxicity in the critically ill. Anaesth Intensive Care 2015;43(5):594-599. http://www.ncbi.nlm. nih.gov/pubmed/26310409. Accessed May 22, 2016.

15. Man SSK, Carr RR, Ensom MHH. Comparison of Continuous and Intermittent IV Infusion of Vancomycin: Systematic Review. Can J Hosp Pharm 2010;63(5):373-381. http://www.pubmedcentral.nih.gov/articlerender.fcgi? artid=2999369\&tool=pmcentrez\&rendertype=abstract. Accessed May 22, 2016.

16. Wysocki M, Delatour F, Faurisson F, et al. Continuous versus intermittent infusion of vancomycin in severe Staphylococcal infections: prospective multicenter randomized study. Antimicrob Agents Chemother 2001;45(9):2460-2467. http://www. pubmedcentral.nih.gov/articlerender.fcgi?artid=90678\&tool=pmcentrez\&rendertype=abstract. Accessed May 22, 2016. 